\title{
EDUCAÇÃO ESPECIAL E ATENDIMENTO EDUCACIONAL ESPECIALIZADO: UM ESTADO DA ARTE
}

Ana Mayra Samuel Silva ${ }^{1}$, Ana Virginia Isiano Lima ${ }^{1}$, Danielle Aparecida do Nascimento Santos ${ }^{2}$, Janiele de Souza Santos ${ }^{3}$, Denner Dias Barros ${ }^{3}$, Elisa Tomoe Moriya Schlünzen ${ }^{4}$

Universidade Estadual Paulista Júlio de Mesquita Filho - FCT/UNESP. ${ }^{1}$ Curso de Pedagogia, Presidente Prudente - SP. ${ }^{2}$ Mestre em Educação, Presidente Prudente - SP. ${ }^{3}$ Curso de Matemática, Presidente Prudente - SP. ${ }^{4}$ Professora assistente - autárquica, Presidente Prudente - SP. E-mail: ana.mayra.ss@gmail.com Órgão de Fomento: Coordenação de Aperfeiçoamento de Pessoal de Nível Superior (CAPES).

\section{RESUMO}

O presente artigo versa sobre as atividades de pesquisa de um projeto vinculado ao Observatório da Educação (OBEDUC) proposto para o biênio 2013-2015. Desenvolvido no âmbito da Faculdade de Ciências e Tecnologia (FCT) - Universidade Estadual Paulista “Júlio de Mesquita Filho" (Unesp), campus de Presidente Prudente/SP, o objetivo desse artigo é apresentar dados coletados em uma revisão documental e bibliográfica do tipo "Estado da Arte" sobre o tema Atendimento Educacional Especializado (AEE). O referencial teórico tem base no histórico das políticas públicas de Educação Especial e de Educação Inclusiva. A coleta de dados foi realizada nas bases legais do AEE no âmbito federal que instituem a Política Pública de Educação Especial na Perspectiva da Educação Inclusiva e em dissertações da instituição produzidas entre 2010 e 2013. O resultado demonstra a importância do AEE para os Estudantes Público Alvo da Educação Especial (EPAEE), e contribui como etapa do projeto OBEDUC.

Palavras-chave: Inclusão Escolar, Educação Especial, Atendimento Educacional Especializado, Estado da Arte, Observatório da Educação.

\section{SPECIAL EDUCATION AND SPECIALIZED EDUCATIONAL SERVICES: A STATE OF THE ART}

\begin{abstract}
This paper discusses research activities of a project linked to the Centre of Education (OBEDUC) proposed for the biennium 2013-2015. Developed within the Faculty of Science and Technology (FCT) - Universidade Estadual Paulista "Júlio de Mesquita Filho" (UNESP), Campus of Presidente Prudente / SP, the aim of this paper is to present data collected in a literature review and documentary-type "State of the Art "on the topic Specialized Educational Assistance (ESA). The theoretical framework is based on the history of public policy for Special Education and Inclusive Education. Data collection was carried out in the legal bases of the federal ESA establishing Public Policy of Special Education in the Perspective of Inclusive Education and the institution dissertations produced between 2010 and 2013 The result demonstrates the importance of the ESA for the Target Audience Students Special Education (EPAEE), and contributes to the step OBEDUC project.
\end{abstract}

Keywords: Inclusion School, Special Education, Specialized Education Services, State of the Art, Education Observatory. 


\section{INTRODUÇÃO E OBJETIVO}

$\mathrm{Na}$ antiguidade as pessoas que nasciam ou adquiriam deficiências, fossem elas físicas ou intelectuais eram excluídas da sociedade e muitas vezes eram até exterminadas, por ser considerado que não apresentavam valor social.

No século XVI, mediante iniciativas de educação para esse público, iniciou-se o período de segregação das pessoas com deficiências em instituições mantidas pela Igreja. Com a Revolução Burguesa, a Igreja Católica perdeu seu poder absoluto e proliferaram-se os experimentos científicos com base na observação da natureza.

Após o término da Segunda Guerra Mundial, ao final da década de 1940 e início de 1950, a luta pela inclusão das pessoas com deficiências foi fortalecida no mundo todo. O processo de integração escolar iniciou-se na Dinamarca, em 1960, com um movimento que reivindicava o direito de acesso das pessoas com deficiência à educação em escolas regulares.

Com isso, observa-se que ao longo da história, a Educação Especial foi oferecida a pessoas com deficiência por instituições filantrópicas e devocionais. Esse oferecimento, considerando um público específico, foi caracterizado por um atendimento clínico e educacional especializados.

Para Mantoan (2005), "inclusão é a nossa capacidade de entender e reconhecer o outro e assim, ter o privilégio de conviver e compartilhar com pessoas diferentes de nós". Para a autora, a educação inclusiva é o acolhimento de todas as pessoas sem exceções, independente de suas características. De acordo com Fernandes (2007),

[...] o movimento de inclusão ambienta-se na década de 1990 objetivando alcançar todas as crianças apoiando nos princípios de igualdade e equiparação de oportunidades na educação. $O$ direito à igualdade de oportunidade resguarda a prerrogativa de que cada um tem interesses e características e que necessitam que sejam atendidas no processo educacional. A equidade assegura que nenhuma manifestação de dificuldades seja impedimento à aprendizagem do aluno, respeitando sempre diferenças individuais. (p.35)

Portanto, considerando as diferenças individuais como condição humana, que não deve ser prerrogativa para definir direitos e oportunidades, o conceito de inclusão passou a fazer referência também aos Estudantes Público-Alvo da Educação Especial (EPAEE): estudantes com deficiência (Auditiva, Física, Intelectual e Visual), transtornos globais de desenvolvimento e altas habilidades ou superdotação, assim como a todos os indivíduos incluídos na escola. Sendo assim, a sociedade e a escola devem estar preparados para acolhê-los, respeitando e valorizando as diferenças individuais que os caracterizam como público da Educação Especial. 
A Educação Especial hoje insere-se em todos os níveis da Educação Escolar, desde a Educação Básica (educação infantil, educação fundamental e ensino médio) até a Educação Superior, bem como nas demais modalidades da educação escolar como a educação de jovens e adultos, a educação profissional e a educação indígena. Conforme Souza (2010, p.72), "a Educação Especial se caracteriza pelo Atendimento Educacional Especializado (AEE), por meio do qual o sistema educacional disponibiliza os recursos e serviços próprios desse atendimento", abrangendo a função de orientar os estudantes e os professores a fim de validar a inclusão escolar dos EPAEE. Sendo assim, a Educação Especial é definida como:

A modalidade de ensino que se caracteriza por um conjunto de recursos e serviços educacionais especiais organizados para apoiar, suplementar e, em alguns casos, substituir os serviços educacionais comuns, de modo a garantir a educação formal dos educandos que apresentem necessidades educacionais muito diferentes das da maioria das crianças e jovens. Tais educandos, também denominados de "excepcionais", são justamente aqueles que hoje têm sido chamados de "alunos com necessidades educacionais especiais". (MAZZOTTA, 2003).

A Lei de Diretrizes e Bases da Educação Nacional no. 9394/96, em seu Capítulo V, Art. 58, define Educação Especial como,

a modalidade de educação escolar, oferecida preferencialmente na rede regular de ensino, para educandos portadores de necessidades especiais.

§1 Haverá, quando necessário, serviços de apoio especializado, na escola regular, para atender as peculiaridades da clientela de educação especial.

§2ㅇ O atendimento educacional será feito em classes, escolas ou serviços especializados, sempre que, em função das condições específicas dos alunos, não for possível a sua integração nas classes comuns do ensino regular.

Com isso, mediante as Diretrizes Nacionais para a Educação Especial ficou determinado aos sistemas de ensino o dever de matricular todos os estudantes, organizando-se para o atendimento aos EPAEE, e fornecendo as condições necessárias para a sua aprendizagem com qualidade. Esses estudantes, portanto, passaram a ter o direito de receber um Atendimento Educacional Especializado (AEE) como serviço de apoio complementar e/ou suplementar à classe comum. $\mathrm{O}$ AEE pode ser caracterizado como um serviço de educação especial que "[...] identifica, elabora e organiza recursos pedagógicos e de acessibilidades, que eliminem as barreiras para a plena participação dos alunos, considerando suas necessidades específicas" (SEESP/ MEC, 2008, p.16) e pode ser realizado em Salas de Recursos Multifuncionais (SRM), serviço de itinerância, intérprete de Língua Brasileira de Sinais (Libras) ou serviço domiciliar e hospitalar. 
Nesse sentido, esse atendimento é destinado aos EPAEE e deve ser realizado preferencialmente nas SRM dentro da escola regular, complementando ou suplementando o ensino formal por um professor especialista, visando a autonomia do estudante na escola e fora dela, constituindo oferta obrigatória pelos sistemas de ensino.

Com base em premissas históricas e legais sobre o processo de inclusão escolar, por meio do Decreto no 5.803/06 foi instituído o projeto OBEDUC ${ }^{1}$. Os pesquisadores da FCT/Unesp desenvolvem via OBEDUC um projeto intitulado "Tecnologia Assistiva e Atendimento Educacional Especializado: um mapeamento sobre as estratégias, práticas, serviços e recursos de acessibilidade no processo de inclusão escolar de estudantes público-alvo da Educação Especial".

A equipe do projeto é multidisciplinar, formada por subequipes que trabalham nas áreas de estatística, tecnologia e pedagógica. Dessa forma, a Equipe Pedagógica realizou uma pesquisa documental e bibliográfica do tipo "Estado da Arte" a fim de expor o significado do AEE e como a política educacional brasileira foi delineando a sua função e contexto. Sendo assim, o objetivo desse artigo é apresentar dados coletados em uma revisão documental e bibliográfica do tipo "Estado da Arte" sobre o tema "Atendimento Educacional Especializado".

\section{MÉTODO}

O método adotado para investigação teve uma abordagem qualitativa, englobando pesquisa documental e pesquisa bibliográfica. De acordo com Pimentel (2001, p. 179), a partir da pesquisa documental,

São descritos os instrumentos e meios de realização da análise de conteúdo, apontando o percurso em que as decisões foram sendo tomadas quanto às técnicas de manuseio de documentos: desde a organização e classificação do material até a elaboração das categorias de análise.

A pesquisa bibliografia, de acordo com Marconi e Lakatos (1992, p. 43), é o levantamento de toda bibliografia já publicada em forma de livros, artigos, revistas, publicações imprensas escritas e avulsas. Tendo por finalidade colocar "o pesquisador em contato direto com tudo aquilo que foi escrito sobre determinado assunto", fazendo-Ihe sabedor das informações já produzidas que podem lhe orientar no rumo a seguir durante sua pesquisa.

Para esta investigação foram realizadas pesquisa documental e bibliográfica, do tipo "Estado da Arte", que tem por finalidade possibilitar ao investigador: a sistematização da produção abrangendo toda uma área do conhecimento; o delineamento dos caminhos da

\footnotetext{
${ }^{1}$ Programa de fomento para o desenvolvimento de estudos e pesquisas em educação, sob a gestão conjunta da Fundação Coordenação de Aperfeiçoamento de Pessoal de Nível Superior (CAPES), do Instituto Nacional de Estudos e Pesquisas Educacionais Anísio Teixeira (INEP) e da Secretaria de Educação Continuada, Alfabetização, Diversidade e Inclusão (SECADI), do MEC.
} 
pesquisa; a observação sobre tendências teórico-metodológicas dos trabalhos analisados; a construção de uma visão geral sobre a produção da área; o diagnóstico sobre a evolução das pesquisas, suas características e foco; podendo ainda, identificar as lacunas ainda existentes.

Inicialmente foram reunidos documentos da legislação educacional, a fim de conhecer e identificar as medidas tomadas pelo governo frente à Educação Especial. Dentre os documentos destacamos a Constituição Federal de 1988, o Estatuto da Criança e do Adolescente (ECA, lei no 8.069/90), a Declaração Mundial de Educação para Todos (1990), a Declaração de Salamanca (1994), a Lei de Diretrizes e Bases da Educação Nacional (Lei no 9.394/96) e a Política Nacional de Educação Especial na Perspectiva da Educação Inclusiva (2007).

Após esse levantamento documental a pesquisa foi direcionada ao banco digital de dissertações e teses do Programa de Pós-Graduação em Educação da Faculdade de Ciências e Tecnologia/Unesp, com o intuito de analisar o que vem a instituição tem produzido atualmente sobre o tema. De acordo com Gil (1987, p.66), dissertações são “importantes para a pesquisa, pois muitas delas são constituídas por relatórios de investigações científicas originais ou acuradas revisões bibliográficas. Seu valor depende [...] da qualidade dos cursos das instituições onde são produzidas e da competência do orientador".

Essa pesquisa foi conduzida pelo uso do descritor "Atendimento Educacional Especializado", e o recorte temporal foi centrado entre os anos de 2010 a 2013, considerando a implementação da Política Nacional de Educação Especial na Perspectiva da Educação Inclusiva, que foi efetivada em 2008 e o desenvolvimento do Programa de Implementação de Salas de Recursos Multifuncionais, efetivado em 2010. A partir dos resultados quantitativos dessa análise inicial, trazemos como resultados a quantidade e qualidade dos trabalhos publicados sobre a temática.

\section{RESULTADOS}

A análise no banco digital de dissertações e teses do Programa de Pós-Graduação em Educação da FCT/Unesp, permitiu-nos encontrar um total de dez (10) dissertações, entre as cento e vinte e três (123) dissertações publicadas pelo Programa de Pós-Graduação em Educação.

Tais dissertações estão distribuídas da seguinte forma: 


\begin{tabular}{|c|c|c|c|c|}
\hline $\begin{array}{c}\text { Dissertações } \\
\text { (FCT - UNESP) }\end{array}$ & $\mathbf{2 0 1 0}$ & $\mathbf{2 0 1 1}$ & $\mathbf{2 0 1 2}$ & $\mathbf{2 0 1 3}$ \\
\hline RELACIONADAS AO TEMA AEE & 2 & 3 & 2 & 3 \\
\hline TOTAL & 29 & 40 & 29 & 25 \\
\hline
\end{tabular}

A análise dos resumos das dissertações encontradas permitiu-nos detectar que foi dada uma abordagem aos assuntos referentes à Inclusão Escolar, Educação Especial e Atendimento Educacional Especializado. As pesquisas se referiam a temas como: Projeto Político Pedagógico, práticas educativas, formação de professores para o trabalho pedagógico com EPAEE, organização escolar, acessibilidade, objetos de aprendizagem, recursos pedagógicos, sala de recursos multifuncionais, além de que uma parte das pesquisas são centradas em determinadas características do público-alvo da Educação Especial como: autismo, deficiência auditiva, deficiência intelectual e deficiência visual. Todas as dissertações trazem no corpo do texto a definição de AEE.

\section{DISCUSSÃO}

A perspectiva da inclusão escolar atual atende às políticas públicas educacionais brasileiras, uma vez que os marcos legais encontrados na Constituição Federal de 1988, no Estatuto da Criança e do Adolescente (ECA, lei no 8.069/90), na Declaração Mundial de Educação para Todos (1990), na Declaração de Salamanca (1994), na Lei de Diretrizes e Bases da Educação Nacional, Lei no 9.394/96 e na Política Nacional de Educação Especial na Perspectiva da Educação Inclusiva (2007) passaram a influenciar a formulação das políticas públicas de educação inclusiva dispondo que toda e qualquer pessoa tem garantido o direito de estudar em escolas de ensino regular e, acima de tudo, aprender nesses ambientes.

Perrenoud (2000, p. 28), afirma que as chances de aprender devem ser asseguradas a todos os indivíduos independente de suas condições socioculturais. Dessa forma, a LDB no. 9394/96 garante "o atendimento educacional especializado gratuito aos educandos com necessidades especiais, preferencialmente na rede regular de ensino", sendo assim "o conhecimento sobre legislação é importante, pois possibilita a todos lutarem pelos direitos quando estes não forem respeitados". (BORGES, 2011, p. 105)

As condições de acessibilidade dispostas nas SRM são viabilizadas pela Tecnologia Assistiva (TA) que, como área de conhecimento, abrange e engloba recursos como: comunicação alternativa, acessibilidade ao computador, acessibilidade de páginas da internet, atividades de 
vida diárias, orientação e mobilidade, adequação postural, adaptação de veículos, órteses e próteses, entre outros (BRASIL, 2006). Além disso, a TA favorece a resolução de problemas funcionais para o desenvolvimento de potencialidades humanas, valorizando os desejos, as habilidades, e as expectativas positivas e de qualidade de vida dos EPAEE.

Conforme Omodei (2013, p.52) o AEE não pode ser caracterizado como reforço escolar, tampouco atendimento clínico. Sobre esse aspecto, é importante dizer que o atendimento clínico pode ser necessário e, em muitos casos, imprescindível. Entretanto, é preciso esclarecer que esse atendimento é distinto do atendimento pedagógico que caracteriza o AEE na SRM, por isso, deve ocorrer paralelamente.

De acordo com Barbosa (2011, p.99)

A organização do Atendimento Educacional Especializado considera as peculiaridades de cada aluno. Alunos com a mesma deficiência podem necessitar de atendimentos diferenciados. Por isso, o primeiro passo para se planejar o Atendimento não é saber as causas, diagnósticos, prognóstico da suposta deficiência do aluno.

Nesse sentido, todo o planejamento das atividades desenvolvidas mediante o AEE deve levar em consideração as especificidades de cada estudante, além de que deve-se considerar todos os envolvidos no processo, desde a equipe gestora aos funcionários da escola, além da importância de uma formação continuada de qualidade para os professores da classe comum e dos que atuam na Educação Especial.

\section{CONCLUSÃO}

Por meio da pesquisa documental e bibliográfica do tipo "Estado da Arte" realizada foi possível compreender o significado do AEE e como a legislação tem delineado a sua função no contexto da inclusão escolar. Sendo assim, podemos concluir que por meio do AEE surge no ambiente escolar a perspectiva de transpor as barreiras impressas junto à dificuldade física e/ou intelectual dos EPAEE, mas também a necessidade de implementar práticas que viabilizem as condições adequadas para que esse serviço seja desenvolvido em uma perspectiva inclusiva.

\section{REFERÊNCIAS}

BARBOSA, Meiriene Cavalcante. Do Preferencial ao Necessário: O Atendimento Educacional Especializado na Escola Comum.2011. 179 f. Dissertação (Mestrado em Educação) - Universidade Estadual de Campinas, Campinas, 2011. 
BORGES, Maria A. A Inclusão de Alunos com Deficiência em Cursos Presenciais de Graduação da Universidade Federal de Juiz de Fora. 2011. 147 f. Dissertação (Mestrado em Educação) Faculdade de Ciências e Tecnologia, Universidade Estadual Paulista, Presidente Prudente, 2011.

BRASIL. Constituição (1988). Texto Constitucional de 5 de outubro de 1988, com as alterações adotadas pelas Emendas Constitucionais no 1/92 a no 28/2000 e Emendas Constitucionais de Revisão no 1 a no 6/94. Brasília: Senado Federal, Subsecretaria de Edições Técnicas, 2000.

BRASIL. Estatuto da Criança e do Adolescente. Lei Federal no 8069, de 13 de julho de 1990. Índice elaborado por Edson Seda. Curitiba: Governo do Estado do Paraná, 1994.

BRASIL: Ministério da Educação. Secretaria da Educação Especial. Atendimento Educacional Especializado: Deficiência Física. Brasília: MEC/SEESP, 2008.

BRASIL. Ministério da Educação. Secretaria de Educação Especial. Diretrizes Nacionais para a Educação Especial na Educação Básica. Brasília: MEC/SEESP, 2001.

BRASIL: Ministério da Educação. Secretaria de Educação Especial. Sala de Recursos Multifuncionais: espaços para o Atendimento Educacional Especializado. Brasília: MEC/SEESP, 2006.

BRASIL: Ministério da Educação. Secretaria de Educação Especial. Política Nacional de Educação Especial na perspectiva da Educação Inclusiva. Brasília: MEC/SEESP, 2007.

GIL, Antonio C. Como Elaborar Projetos de Pesquisa. São Paulo: Atlas, 1987.

MANTOAN, Maria Teresa Eglér. Inclusão é o Privilégio de Conviver com as Diferenças. In Nova Escola, maio, 2005.

MARCONI, Marina A; LAKATOS, Eva M. Metodologia do Trabalho Científico. São Paulo: Atlas, 1992.

MAZZOTTA, M. J. S. Educação Especial no Brasil: História e Políticas Públicas. 4. ed. São Paulo: Cortez, 2003.

OMODEI, Juliana Dalbem. Um olhar para a sala de recursos multifuncionais e objetos de aprendizagem: apontamentos de uma pesquisa e intervenção. 2014. 186 f. Dissertação (Mestrado em Educação) - Faculdade de Ciências e Tecnologia, Universidade Estadual Paulista, Presidente Prudente, 2013.

PERRENOUD, Philippe. Pedagogia diferenciada: das intenções à ação. Trad. PatríciaChittoni Ramos. Porto Alegre: Artes Médicas Sul, 2000.

PIMENTEL, A. O método da análise documental: seu uso numa pesquisa histórica. Cadernos de Pesquisa, n.114, p.179-195, nov., 2001.

SOUZA, Daniela C. B. A inclusão na perspectiva da organização pedagógica de escolas públicas e privadas. 2010. 160 f. Dissertação (Mestrado em Educação) - Faculdade de Ciências e Tecnologia, Universidade Estadual Paulista, Presidente Prudente, 2010. 
UNESCO. Declaração de Salamanca. Sobre Princípios, Políticas e Práticas na Área das Necessidades Educativas Especiais. Disponível em: <http://goo.gl/aJbxeD> Acesso em: 04 jun. 2014.

UNESCO. Declaração mundial sobre educação para todos: satisfação das necessidades básicas de aprendizagem. Jomtien, 1990. 